\title{
Outcomes following mepolizumab treatment discontinuation: real-world experience from an open-label trial
}

\author{
Hector Ortega ${ }^{1,8^{*}}$, Catherine Lemiere ${ }^{2,3}$, Jean-Pierre Llanos ${ }^{4}$, Mark Forshag ${ }^{4}$, Robert Price ${ }^{5}$, Frank Albers ${ }^{6}$, \\ Steven Yancey ${ }^{6}$ and Mario Castro ${ }^{7}$
}

\begin{abstract}
Limited information is available on the clinical course of patients with severe asthma following discontinuation of biologic treatment. Therefore, a post hoc analysis was conducted in patients with severe eosinophilic asthma who participated in the COSMOS trial, where patients received mepolizumab for more than 1 year of continuous therapy. The objective of this post hoc analysis was to evaluate changes in the Asthma Control Questionnaire (ACQ-5) and blood eosinophil counts 12 weeks after the last administration of mepolizumab. Cessation of mepolizumab was associated with a rise in the blood eosinophil count and loss of asthma control after stopping therapy. These data suggest that patients with severe disease require extended and continuous treatment. Further studies evaluating longer duration of continuous treatment with mepolizumab could help understanding of whether changes in the presentation of the disease (disease modification) are possible with the use of biologics, such as mepolizumab.
\end{abstract}

Keywords: Severe eosinophilic asthma, Cessation of treatment, Asthma control, Blood eosinophils

\section{To the Editor:}

\section{Background}

Asthma is a heterogeneous disease with diverse characteristics and biologic mechanisms. Current asthma guidelines offer a helpful framework for managing patients; however, some patients remain uncontrolled despite aggressive treatment interventions. The major goal of these guidelines is to achieve disease control and reduce the risk of future deterioration $[1,2]$. Although the guidelines do discuss the management of patients with severe asthma, they were not designed for a phenotype or endotype-driven approach to care. Personalized treatment interventions for Th2-high asthma do not benefit all individuals since not all patients have Th2-high disease. Stratification of asthma subtypes (i.e., phenotypes and endotypes) with appropriate use

\footnotetext{
*Correspondence: hortega@gossamerbio.com

8 Present Address: Gossamer Bio, 3013 Science Park Rd, Suite 200, San Diego, CA 92121, USA

Full list of author information is available at the end of the article
}

of biomarkers can help patient selection and guide management. The use of biomarkers (both clinical and lab-based) that are easily measured and consistently reliable is essential. In the case of severe eosinophilic asthma, the use of blood eosinophils as a biomarker to select the patients most likely to benefit with antiinterleukin 5 (anti-IL5) therapies has been established [3-5]. Similarly, clinical markers of uncontrolled asthma including a recent history of exacerbations despite optimized treatment, or uncontrolled asthma based on asthma control (e.g., ACQ or ACT) are relevant tools in the assessment of these patients. Recently, several biologics have been approved for the treatment of patients with severe asthma. However, there are critical questions when a patient with severe asthma initiates treatment with a biologic, such as the length of treatment duration and potential consequences after stopping treatment. The current report evaluated changes that occurred following mepolizumab (anti-IL5 monoclonal antibody) therapy cessation after more than 1 year of continuous therapy. 


\section{Methods}

COSMOS [6] was a 52-week, multicenter, open-label, phase IIIb study that assessed the safety of mepolizumab $100 \mathrm{mg}$ subcutaneous (SC) in patients $(\mathrm{N}=651)$ with severe eosinophilic asthma (NCT01842607). Eligible patients were $\geq 12$ years of age, who upon completion of randomized studies MENSA [3] (NCT01691521) or SIRIUS [4] (NCT01691508) immediately commenced the COSMOS trial. Mepolizumab $100 \mathrm{mg}$ SC was administered every 4 weeks with the last dose administered at week 48. At week 60, patients (57\%) who did not immediately enter a subsequent open-label extension (COSMEX, Study ID 201312) returned to clinic for a follow-up visit. The subsequent COSMEX study was designed to enroll patients with the most severe form of asthma (as identified by previous intubations, hospitalizations, exacerbations and maintenance oral corticosteroids use) in patients who had previously demonstrated benefit from mepolizumab treatment. This approach ensured that mepolizumab treatment was available for an extended period for those with the greatest unmet medical need.

In the current analysis, ACQ-5 and blood eosinophil counts were chosen as their deterioration may predict subsequent asthma worsening as well as exacerbations and increases in oral corticosteroid dose. ACQ-5 and blood eosinophils were measured at weeks 4, 16, 28, 40 (ACQ-5 only), 52 (exit visit; 4 weeks after the last administration of mepolizumab), and 60 (follow-up). Values of the endpoints measured are presented as means with $95 \%$ confidence intervals (CI) to show measure of spread, in addition to presenting the proportion of subjects above and below an ACQ-5 score and blood eosinophil count of 1.5 and 150 cells $/ \mu \mathrm{L}$, respectively.

\section{Results}

Upon completion of mepolizumab treatment (week 52 ) in the COSMOS study, the mean ACQ-5 score was 1.31 (95\% CI 1.22-1.40). ACQ-5 measured 12 weeks after the last administration of mepolizumab (week 60) showed a reduction in asthma control (movement in ACQ-5 values to $\geq 1.5$, reflective of uncontrolled asthma) with a mean ACQ-5 score of 1.66 (95\% CI 1.52-1.80) (Fig. 1a). For patients completing both the exit visit and the follow-up visit (weeks 52 and 60), ACQ-5 mean score increased, indicating a worsening in asthma symptoms, from 1.28 (95\% CI 1.16-1.40; $\mathrm{n}=326)$ at week 52 to 1.65 (95\% CI 1.51-1.79; $\mathrm{n}=357)$ at week 60. Overall, of the 592 patients with data available, almost two-thirds $(\mathrm{n}=372)$ had an ACQ-5 score below the 1.5 threshold at week 52 , and by week 60 this had decreased to about half $(188 / 365)$.

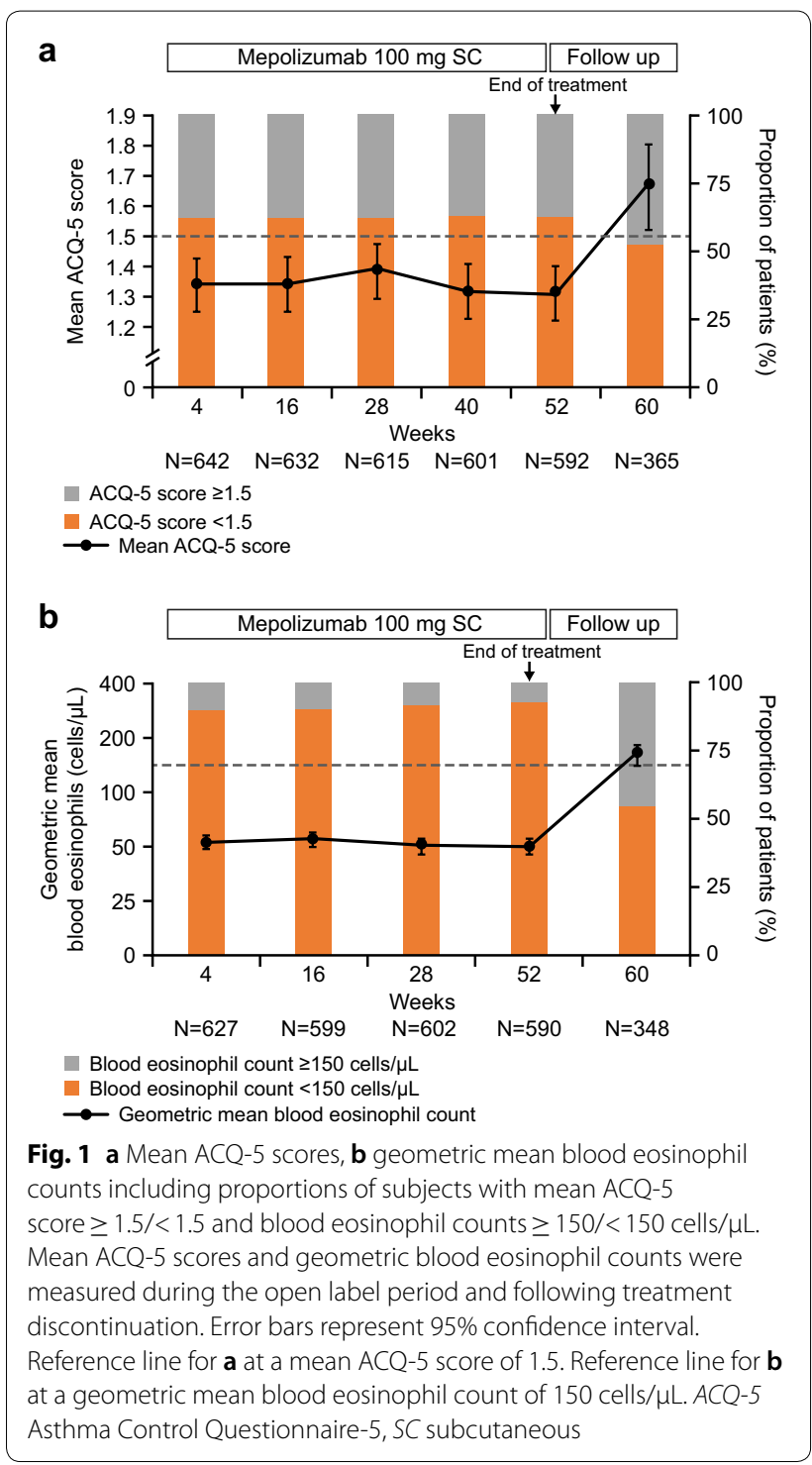

As reported previously by Lugogo et al. [6], the geometric mean of blood eosinophils was 48 cells $/ \mu \mathrm{L}$ (95\% CI 45-52) at week 52. Following cessation of mepolizumab treatment, eosinophil counts measured at week 60 increased to a geometric mean of 159 cells $/ \mu \mathrm{L}$ (95\% CI 141-179) (Fig. 1b). For patients completing both the exit visit and the follow-up visit (weeks 52 and $60)$, blood eosinophil counts (geometric mean) also increased from 45 cells/ $\mu \mathrm{L}$ (95\% CI 40-49; $\mathrm{n}=327)$ at week 52 to 158 cells $/ \mu \mathrm{L}(95 \%$ CI $140-178 ; \mathrm{n}=338)$ at week 60. Overall, for blood eosinophil counts at week $52,91 \%$ of patients $(536 / 590)$ had a count below 150 cells $/ \mu \mathrm{L}$, which decreased to $43 \%$ (149/348) by week 60 . 


\section{Discussion}

The increase in the mean ACQ- 5 score (0.35 points) 8 weeks after treatment cessation, although not considered clinically significant, suggests that patients began to experience a worsening of asthma control only a few weeks following cessation of mepolizumab treatment. In addition, at 12 weeks after the last administration of mepolizumab (week 60) the mean ACQ-5 scores were similar to the values reported at baseline, demonstrating that when treatment with mepolizumab was discontinued patients' asthma symptoms showed signs of worsening and in parallel blood eosinophils increased. The threshold of 150 cells $/ \mu \mathrm{L}$ has previously been associated with the responder phenotype to mepolizumab treatment [3-5].

Our findings are consistent with a previous study by Haldar et al. [7] in patients with severe eosinophilic asthma $(\mathrm{N}=56)$ who experienced a significant increase in blood eosinophil counts after discontinuation of mepolizumab and a subsequent clinical deterioration, i.e., at 12 months following discontinuation of mepolizumab, the mean modified Juniper Asthma Control Questionnaire score increased by 0.59 points to an estimated score of $2.29(\mathrm{p}<0.001)$ [7]. This study by Haldar and colleagues also addressed the question regarding rebound, which is defined as an exaggerated pharmacodynamic response following treatment cessation above baseline values. In their study as well as in the current analysis, the return of symptoms and mean blood eosinophil counts were not seen to exceed baseline values at the start of treatment.

A limitation of the current study was the lack of a control arm, and thus between-study comparisons should be made with caution. The fact that more severe patients entered the COSMEX extension study could have introduced some selection bias in those subjects attending the follow-up visit. However, consistent results were observed following analyses of the overall study population and when restricted to only subjects completing both the exit visit and the follow-up visit (weeks 52 and 60). Furthermore, mean values of the ACQ-5 and blood eosinophil data at the end of the COSMOS study (week 52) were similar to baseline values in those patients who entered the COSMEX study with continuous treatment. In addition, we were unable to extend our observations beyond 12 weeks after the last administration of mepolizumab and therefore it is unknown if a further deterioration occurred in these patients. Another limitation is that the dose of other controller medications was not regulated throughout the study period. As such, it is difficult to establish comparisons with controlled clinical trials in which controller medication use is regulated. However, this lack of controller use regulation should be considered to reflect the realworld clinical experience of patients receiving longterm mepolizumab treatment. Overall, these data highlight the importance for continuous treatment with a biologic based on changes in key clinical outcomes after discontinuation of mepolizumab treatment.

\section{Abbreviations}

ACQ-5: Asthma Control Questionnaire-5; ACT: Asthma Control Test; anti-IL5: anti-interleukin-5; Cl: confidence interval; SC: subcutaneous.

\section{Acknowledgements}

Editorial support (in the form of formatting and grammatical editing) was provided by Susan Parker, Ph.D., of Fishawack Indicia Ltd, UK, funded by GSK.

\section{Authors' contributions}

$\mathrm{HO}, \mathrm{RP}$ and SWY contributed to study design and conception, and data analysis and interpretation. CL contributed to the acquisition of data, and data analysis and interpretation. FA, MF, JP-L and MC contributed to data analysis and interpretation. All authors contributed to manuscript development. All authors read and approved the final manuscript.

\section{Funding}

This study (GSK study ID MEA115661/NCT01842607) and the primary studies (GSK study ID MEA115588/NCT01691521 and GSK study ID MEA115575/ NCT01691508) were sponsored by GSK.

\section{Availability of data and materials}

Anonymized individual participant data from the studies listed within this publication and their associated documents can be requested for further research from www.clinicalstudydatarequest.com.

\section{Ethics approval and consent to participate}

This was a post hoc analysis of the COSMOS study. The original study protocol was approved by the appropriate investigational center ethics committee or institutional review board in accordance with the International Conference on harmonization of Technical Requirements for Registration of Pharmaceuticals for Human Use (ICH) Good Publication Practice (GPP). All patients provided their consent.

\section{Consent for publication}

Not applicable.

\section{Competing interests}

$\mathrm{HO}$, J-P LL, MF, RP, FA and SY are employees of GSK and own stock/stock options in GSK. CL has attended advisory boards for AstraZeneca, GSK, Teva and Methapharm; received consulting fees from AstraZeneca, Teva and Methapharm; and received research funding from AstraZeneca and Teva. MC has received consulting fees from Genentech, Teva, Sanofi-Aventis, Aviragen, Boston Scientific and Holaira; received speaker fees from Genentech, Boston Scientific, Teva, Boehringer-Ingelheim and AstraZeneca; received research funding from Teva, GSK, Sanofi-Aventis, Vectura, Boehringer-Ingelheim, Invion, AstraZeneca, Gilead, Novartis and Chiesi; has participated on GSK Data Safety Monitoring Committee; and received royalties from Elsevier.

\footnotetext{
Author details

${ }^{1}$ Respiratory US Medical Affairs, GlaxoSmithKline, La Jolla, CA, USA. ${ }^{2}$ Faculty of Pharmacy, Université de Montréal, Montreal, QC, Canada. ${ }^{3}$ Research Centre, Hôpital du Sacré-Cœur de Montréal, Montreal, QC, Canada. ${ }^{4}$ Respiratory US Medical Affairs, GlaxoSmithKline, Research Triangle Park, NC, USA.

${ }^{5}$ Clinical Statistics, GlaxoSmithKline, Stockley Park, Uxbridge, Middlesex, UK. ${ }^{6}$ Respiratory Therapeutic Area Unit, GlaxoSmithKline, Research Triangle Park, NC, USA. ${ }^{7}$ Division of Pulmonary and Critical Care Medicine, Washington University School of Medicine, St. Louis, MO, USA. ${ }^{8}$ Present Address: Gossamer Bio, 3013 Science Park Rd, Suite 200, San Diego, CA 92121, USA.
} 
Received: 13 December 2018 Accepted: 30 May 2019

Published online: 10 June 2019

\section{References}

1. Global Initiative for Asthma. Global strategy for asthma management and prevention. Updated 2018. https://ginasthma.org/2018-gina-repor t-global-strategy-for-asthma-management-and-prevention/. Accessed 06 Dec 2018.

2. National Asthma Education and Prevention Program. Expert Panel Report 3 (EPR-3): guidelines for the diagnosis and management of asthmasummary report 2007. J Allergy Clin Immunol. 2007;120:594-138.

3. Ortega HG, Liu CM, Pavord ID, Brusselle GG, FitzGerald JM, Chetta A, et al. Mepolizumab treatment in patients with severe eosinophilic asthma. N Engl J Med. 2014;371:1198-207.

4. Bel EH, Wenzel ES, Thompson JP, Prazma CM, Keene NO, Yancey WS, et al. Oral glucocorticoid-sparing effect of mepolizumab in eosinophilic asthma. N Engl J Med. 2014;371:1189-97.
5. Ortega H, Yancey WS, Mayer B, Gunsoy BN, Keene NO, Bleecker ER, et al. Severe eosinophilic asthma treated with mepolizumab stratified by baseline eosinophil thresholds: a secondary analysis of the DREAM and MENSA studies. Lancet Respir Med. 2016;4:549-56.

6. Lugogo N, Domingo C, Chanez P, Leigh R, Gilson JM, Price GR, Yancey WS, Ortega GH. Long-term safety and efficacy of mepolizumab in patients with severe eosinophilic asthma: a multi-centre, open-label, phase IIIb study. Clin Ther. 2016;38:2058-70.

7. Haldar P, Brightling EC, Singapuri A, Hargadon B, Gupta S, Monteiro $W$, et al. Outcomes after cessation of mepolizumab therapy in severe eosinophilic asthma: a 12-month follow-up analysis. J Allergy Clin Immunol. 2014;133:921-3.

\section{Publisher's Note}

Springer Nature remains neutral with regard to jurisdictional claims in published maps and institutional affiliations.
Ready to submit your research? Choose BMC and benefit from:

- fast, convenient online submission

- thorough peer review by experienced researchers in your field

- rapid publication on acceptance

- support for research data, including large and complex data types

- gold Open Access which fosters wider collaboration and increased citations

- maximum visibility for your research: over $100 \mathrm{M}$ website views per year

At BMC, research is always in progress.

Learn more biomedcentral.com/submissions 